\title{
The role of exercise prescription in chronic disease
}

\section{G E Moore}

\section{Appropriate exercise should be included in the treatment of all patients}

T he use of exercise as a medical treatment is an old concept, but one that did not start gaining acceptance until the 20th century. Today, exercise scientists are exploring the limits of exercise as a therapy-of exercise as a medicine. It is not possible to discuss all the ramifications of exercise prescription in a brief article, so I shall take a larger view and illustrate how various kinds of exercise may be useful in patients with a chronic disease and/or a disability.

Hippocrates wrote, "In a word, all parts of the body which were made for active use, if moderately used and exercised at the labor to which they are habituated, become healthy, increase in bulk, and bear their age well, but when not used, and when left without exercise, they become diseased, their growth is arrested, and they soon become old." ${ }^{1}$ Medicine's view of exercise did not progress much in the subsequent two millenia, and exercise was primarily viewed as an activity for healthy people, but not for the chronically ill. The first recorded anecdote of exercise as a treatment for heart disease is thought to be from William Heberden, who wrote of a man with angina pectoris in 1772: "I knew of one who set himself the task of sawing wood for half an hour every day, and was nearly cured". ${ }^{2}$ Ironically, Heberden did not know that angina pectoris is a cardiac disorder.

\section{"McKenzie perceived exercise as a technique to rehabilitate people with disabling injuries"}

Physicians of the 1800s were interested in the role of exercise in maintenance of health, ${ }^{3}$ but the modern notion of exercise as a medical treatment is thought to have originated with R Tait McKenzie. ${ }^{4}$ With a background in boxing, McKenzie held that exercise has many benefits to the human body, and in 1904 he became the chairman of the Department of Physical Education at the University of Pennsylvania. Later, work- ing as a medic during the first world war, McKenzie perceived exercise as a technique to rehabilitate people with disabling injuries. McKenzie recognised that some wounded soldiers can be returned to the battlefield (in which case it is important to obtain a rapid rehabilitation), and that wounded soldiers who are permanently disabled need physical rehabilitation to help them cope with their disabilities. Ever since, military physicians have been biased toward aggressive rehabilitation.

In contrast with McKenzie, most physicians of his era did not value exercise as a clinical treatment. William Osler, in the 1909 edition of The principles and practice of medicine, wrote that bed rest and baths at spas like Bad Nauheim were the optimal treatment for heart disease. ${ }^{5}$ Physicians of the 19th and early 20th centuries were confused by enlargement of the heart, having recognised that cardiac hypertrophy paradoxically occurs both in athletes and patients with heart failure. Only after decades of research did physicians become advocates of exercise as a method of rehabilitation for heart disease. In 1939, Paul Dudley White, the first cardiology professor at Harvard Medical School, co-authored a manuscript showing cardiac dilatation through aneurysm formation after myocardial infarction, and this was used as an argument against exercise after myocardial infarction. ${ }^{6}$ By 1958, Dr White had changed his views and coauthored a textbook on cardiac rehabilitation in which low level exercise was promoted. ${ }^{7}$ Then in 1968, the concept of bed rest was finally put to rest by the landmark paper of Bengt Saltin et al. ${ }^{8}$ In 60 years, physicians had learned that exercise was useful in rehabilitation of people with both musculoskeletal injuries and cardiovascular disease.

Gradually, exercise specialists of all kinds saw rationales for medically directed exercise in many conditions. Pulmonologists, exposed to cardiac rehabilitation concepts, worked hard to promote pulmonary rehabilitation for patients with lung disease; ${ }^{10}$ diabetol- ogists and obesity specialists have recently emphasised exercise as a mainstay of therapy; ${ }^{11}$ geriatricians learned that exercise helps to maintain functional independence in octagenarians and nonagenarians. ${ }^{12}{ }^{13}$ As more people survive in spite of chronic diseases, paradigms for medically directed exercise have been developed for patients burdened with multiple chronic diseases. ${ }^{14}{ }^{15}$ We now even see elite athletes who have chronic conditions or are disabled, who thus have unique needs for sports medical guidance.

In today's Centers for Disease Control and Prevention and the American College of Sports Medicine (CDC/ ACSM) paradigm for exercise prescription, there are two default options for exercise programming: (a) anything a little beyond the patient's current activity level; $(b)$ recommending large muscle group activities for 30-40 minutes on four or more, preferably all, days of the week (stretching and strength training are mentioned in passing). ${ }^{16}$ The first alternative is often used as a starting point in patients with very low exercise tolerance; the second alternative is often used as a goal for maintaining overall hardiness. These guidelines promote the notion of accepting the former if the patient cannot (or will not) achieve, because the vast majority of people need more activity than they are currently doing. This approach has probably been a step forward, but it must be recognised that it is a sociological compromise that falls far short of a true exercise prescription.

An exercise prescription, like any prescription, has a type and dose, a dosing frequency, a duration of treatment, a therapeutic goal, and anticipated adverse effects. This is true whether the exercise is simple stretching for range of motion, aerobic exercise for all around fitness, resistance training for strength, or a more integrated type of functional exercise designed around activities of daily living. Generically speaking, any exercise prescription resembles a drug prescription: Exercise $A$, taken $N$ times daily, for $X$ duration of weeks/months/years. The exercise type and dose are chosen by the person's individual needs, goals, and ability level; the frequency and intensity of each session are chosen by the person's intrinsic endurance and ability to recover; the progression and duration of the programme is determined by the person's intermediate and long term goals. Adverse effects are related to the type of exercise-for example, delayed onset muscle soreness-and the specific chronic disease-for example, chest pain in angina pectoris, joint pain in arthritis, fatigue in fibromyalgia. ${ }^{17}$ To 
prescribe exercise in the context of chronic disease, one needs to consider how the physiology of exercise training interacts with both the pathophysiology and medical management of the patient's chronic disease(s).

\section{"Our current understanding of exer- cise prescription is limited for most chronic diseases"}

Such an exercise prescription is useful in almost all chronic diseases. What we do not know is how to optimise specific kinds of exercise for most clinical conditions. In spite of our scientific progress, our current understanding of exercise prescription is limited for most chronic diseases. Were exercise viewed as a drug, we would not have sufficient evidence for exercise to pass government regulatory requirements for most diseases. ${ }^{18}$ Exercise programming for most conditions must still be achieved somewhat by empiricism and trial and error, and is thus as much an art as it is a science. Most doctors have very little knowledge of exercise or sports, and thus are not schooled in this art, so they do not prescribe exercise and often fail to even recommend exercise to patients who need it the most (unpublished data). To make matters worse, a few doctors refer patients to exercise specialists, who often have insufficient knowledge of disease pathophysiology and do not have direct access to patients $(\mathrm{H}$ Perrault, personal communication, 2002). Our challenge today is to find a better clinical care paradigm in which doctors and exercise specialists (cardiovascular, pulmonary and musculoskeletal) work more closely together to provide medically directed exercise programmes that are appropriate for each patient. We need to revise our curricula of education physicians, exercise specialists, and physiotherapists, so that they are trained to collaborate toward this end.

Owing to historical circumstances highlighted by the careers of Drs McKenzie and White, physiatry and orthopaedics controlled neuromuscular rehabilitation, and cardiology controlled cardiovascular rehabilitation. As a consequence, medically directed exercise has tended to fall into two domains: physiotherapy and cardiovascular/pulmonary rehabilitation. This division is mainly a consequence of "turf" — that is, control of revenue stream-and is counterproductive. It has had the unintended consequence of guiding cardiovascular patients away from musculoskeletal therapists, and physically disabled patients away from cardiovascular therapists. Patients who have both problems have not been well served: in the developed world the number l cause of death among disabled patients is cardiovascular disease. ${ }^{19} 20$ Why then, do we not see more disabled patients in cardiac rehabilitation programmes? The American College of Sports Medicine's textbook Exercise management for persons with chronic diseases and disabilities attempts to overcome this artificial barrier, with half of the book dedicated to chronic diseases and half to disabilities. ${ }^{21}$

Perhaps now is the time to abandon the artificial division of exercise into neuromusculoskeletal and cardiovascular/pulmonary domains. Rather than continuing our reductionist view of exercise as treatment for physiological subsystems, perhaps we should turn toward viewing exercise as a foundation of mind-body medicine. ${ }^{22}$ We should stop thinking of strength training as a specific antidote to muscle atrophy, of aerobic exercise as something specific to the heart, and stretching as a specific antidote to joint tightness. We should start looking at all forms of exercise training as integral to the physical, metabolic, emotional, and spiritual robustness of patients.

Sports medicine doctors, the few physicians who actually know something about both exercise and medicine, ought to be leading this transformation. For every injured athlete, there are a score of patients for whom exercise prescription should be the cornerstone of their medical management. We need more sports medicine doctors carrying out research on important questions such as the exercise dose-response relation in a particular disease, an area in which they are uniquely qualified. We need doctors who view sports medicine as a specialty where exercise is the prescription of choice for all their patients, athlete and non-athlete alike. When we achieve that, perhaps the dream of $\mathrm{R}$ Tait McKenzie will finally be fulfilled.

Br J Sports Med 2004;38:6-7. doi: 10.1136/bjsm.2003.010314

Correspondence to: G E Moore, Healthy Living and Exercise Medicine Associates, 1316 Black River Boulevard, Rome, NY 13440, USA geofmoore@earthlink.net

\section{REFERENCES}

1 Hippocrates. On the articulations. The genuine works of Hippocrates, translated from the Greek with a preliminary discourse and annotations.
London: Sydenham Society, 1849, circa 400 BC:part 58 .

2 Heberden W. Some account of a disorder of the breast. Medical Transactions of the Royal College of Physicians 1772;2:59-67.

3 McArdle WD, Katch FI, Katch VL. Introduction: a view of the past-exercise physiology: roots and historical perspectives. Exercise physiology: energy, nutrition, and human performance, 5th ed. Philadelphia: Lippincott Williams \& Wilkins, 2001, xvii-lxv.

4 Berryman J. Out of many, one: a history of the American College of Sports Medicine. Champaign, IL: Human Kinetics, 1995.

5 Osler W. The principles and practice of medicine: designed for the use of practitioners and students of medicine, 7th ed. New York: D Appleton \& Co, 1909

6 Mallory GK, White PD, Salcedo-Salgar J. The speed of healing on myocardial infarction: a study of the pathologic anatomy in seventy-two cases. Am Heart J 1939; 18:647-56.

7 White PD, Rusk HA, Lee PR, et al. Rehabilitation of the cardiovascular patient. New York: McGrawHill Book Company, Inc, 1958.

8 Saltin B, Blomqvist G, Mitchell JH, et al. Response to exercise after bed rest and after training: a longitudinal study of adaptive changes in oxygen transport and body composition. Circulation 1968;38(suppl vii):VII-1-VII-78.

9 Asakura K. Collaboration of national organizations and the legislative means to advance pulmonary rehabilitation. Respir Care Clin N Am 1998;4:173-81.

10 Celli BR. Standards for the optimal management of COPD: a summary. Chest 1998;113(suppl):283S-287S

11 Brownell KD. The LEARN program for weight management 2000. Dallas: American Health Publishing Company, 2000.

12 Fiatarone MA, Marks EC, Ryan ND, et al. Highintensity strength training in nonagenarians. Effects on skeletal muscle. JAMA 1990;263:3029-34

13 Fiatarone MA, $\mathrm{O}^{\prime}$ Neill EF, Ryan ND, et al. Exercise training and nutritional supplementation for physical frailty in very elderly people. N Engl J Med 1994;330:1769-75.

14 Moore GE, Durstine JL. Framework. In: Durstine JL, Bloomquist LE, Figoni SF, et al., eds. ACSM's exercise management in persons with chronic disease and disability. Champaign, IL: Human Kinetics, 1997:6-16.

15 Moore GE. Exercise prescription in persons with multiple chronic diseases. In: Shankar K, ed. Exercise prescription. Philadelphia: Hanley \& Belfus, Inc, 1998:173-82.

16 Pate RR, Pratt M, Blair SN, et al. Physical activity and public health. A recommendation from the Centers for Disease Control and Prevention and the American College of Sports Medicine. JAMA 1995;273:402-7.

17 Moore GE, Durstine JL, Marsh AP. Framework. In: Durstine JL, Moore GE, eds. ACSM's exercise management for persons with chronic diseases and disabilities, second edition, 2nd ed. Champaign, IL: Human Kinetics, 2002:5-15.

18 Haskell WL. Health consequences of physical activity: understanding and challenges regarding dose-response. Med Sci Sports Exerc 1994;26:649-60

19 Murray CJ, Lopez AD. Global mortality, disability, and the contribution of risk factors: global burden of disease study. Lance 1997:349:1436-42.

20 Phillips WT, Kiratli BJ, Sarkarati M, et al. Effect of spinal cord injury on the heart and cardiovascular fitness. Curr Probl Cardiol 1998;23:641-716.

21 Durstine JL, Moore GE. ACSM's exercise management for persons with chronic diseases and disabilities, 2nd ed. Champaign, IL: Human Kinetics, 2002.

22 Chopra D. Creating health. Boston: HoughtonMifflin, 1987. 